\title{
Determinants of the Adoption of Improved Sorghum and Sesame Seeds; the Case of West Gondar Zone, Ethiopia
}

\author{
Walelgn Yalew ${ }^{1}$, Sisay Yehuala ${ }^{2}$, Tigist Petros ${ }^{2}$ \\ ${ }^{1}$ Department of Agricultural Economics, University of Gondar, Gondar, Ethiopia \\ ${ }^{2}$ Department of Rural Development \& Agricultural Extension, University of Gondar, Gondar, Ethiopia \\ Email address: \\ walelgnyalew@dmail.com (W. Yalew), sisaygon@yahoo.com (S. Yehuala)
}

To cite this article:

Walelgn Yalew, Sisay Yehuala, Tigist Petros. Determinants of the Adoption of Improved Sorghum and Sesame Seeds; the Case of West Gondar Zone, Ethiopia. International Journal of Energy and Environmental Science. Vol. 5, No. 5, 2020, pp. 82-89.

doi: $10.11648 /$ j.ijees.20200505.11

Received: February 27, 2020; Accepted: March 13, 2020; Published: September 30, 2020

\begin{abstract}
Improved Seed is a key input for increasing crop production and productivity. Improving the quality of seeds can increase the yield potential of the crop by significant folds. However, due to the growing demands of the farmers in the study area for improved agricultural inputs, the supply sector could not satisfy the needs of the farmers. This indicates that there are different factors directly or indirectly influencing the input supply system. Hence, this study focuses on the Determinants of the adoption of improved Sorghum and Sesame seeds in West Gondar Zone. The research adopts a cross sectional survey design that combines both qualitative and quantitative research approaches. To conduct this study a multi stage purposive and simple random sampling technique was applied. A total of 150 sample household heads was selected from the two kebeles proportionally to their population size by using systematic random sampling technique. The data were collected from both primary and secondary sources of data. Data analysis was done by using descriptive statistics like frequency, mean, and standard deviation. Moreover, inferential statistics like Chi-square T-test was used to test whether there is a significant difference among the dummy/categorical and continuous variables respectively. The binary logit model was also used. The results of the study indicated that for both the technologies $83(36.4 \%)$ of the sampled farm households were found to be adopters, whereas the remaining $145(63.6 \%)$ were non-adopters. The maximum likelihood estimates of the logistic regression model show that livestock holding in TLU (LSTOCKHO), farming experience (FARMEXP), fertilizer use (FERUSE) and total income (TOTALINCOME) were important and significant factors influencing smallholder farmers' adoption improved sesame seed variety in the study area. The government has to give a great emphasis on the technology dissemination and awareness about the adoption of improved seeds.
\end{abstract}

Keywords: Improved Seed, Binary Logistic Model, Adoption of Improved Seed, Sorghum \& Maize

\section{Introduction}

\subsection{Backgrounds of the Study}

Seeds are basic agricultural input. More importantly quality seeds of any preferred varieties are basis of improved agricultural productivity since they respond to farmers needs for both their increasing productivity and crop uses [1]. Unavailability of improved seeds at the right place and time coupled with poor promotion system, is one of the main factors accounting for limited use of improved seeds, which further contributing for low agricultural productivity in Ethiopia.
To alleviate the problem rural households in Ethiopia are involved in multiple kinds of seed systems, which can guarantee them in obtaining the quantity and quality of seeds they need and to market their produce. Different Seed systems are operating in the country. The formal and the informal system (sometimes called local or farmers seed system). The fact that the formal system is the original source of quality seeds in the informal system. There is also a system which is said as integrated seed system. Other forms of seed systems operating in both systems also exist such as Community Based Seed Multiplication Scheme (CBSMS). Though not well developed, few commercial seed systems, as part of the formal system, are also operating in the country [2]. 
The seed demand is increasing rapidly due to the agricultural development. Thus, securing the supply of quality seed and planting material of the most important food crops is the most effective way to sustain food security in Ethiopia [3]. An effective seed system is the basis for productive agricultural systems. Farmers produce and/or hope to obtain seed that is adapted to their production scheme natural, social, and cultural environments, and market channels. The sources of such seed can be recognized as formal or informal seed supply. The latter is also referred to as the farmers' seed system [4].

Even though much emphasis is placed on the formal seed systems, the informal seed systems are commonly found for almost all crops in the country. The share of formal seed supply was estimated to only $3 \%$ in 2002 , while the area cultivated with modern varieties was estimated to range between 10 and $20 \%[5,6]$.

Due to this reason there is low level of improved technologies utilization and high risk due to adverse environment are among the most frequently mentioned major causes of the country's chronic food security problem. In order to meet the food requirements of the growing population, food grains and other agricultural products have to be increased. The immediate available means to attain the national goal of food self-sufficiency is improving productivity through improved technologies including improved seeds [7].

The former North Gondar Zone now named as West Gondar zone, in its strategic plan, has indicated to increase the productivity of agricultural crops by reasonable figure through improving farmers' utilization of improved seeds. But farmers are complaining about the inadequate seed supply system due to poor supply of the improved Sesame and Sorghum seeds. This shows that how much the seed supply and distribution system is poor and needs attention for further investigation regarding to improved seed supply and distribution system.

Therefore, the researchers initiated to assess the seed supply and distribution systems and the influential factors for the smooth functioning of the system by giving special emphasis on Sesame and Sorghum seeds in the study area.

\subsection{Statement of the Problem}

Improved Seed is a key input for improving crop production and productivity. Increasing the quality of seeds can increase the yield potential of the crop by significant folds and thus, is one of the most economical and efficient inputs to agricultural development [8]. Generation and transfer of improved technologies are critical prerequisites for agricultural development particularly for an agrarian based country like Ethiopian [9]. Although significant public resources are invested in the public plant breeding and multiplication, the products are not reaching farmers. Seed supply chain is a vital link between the seed producers and the farmers that ultimately use the seeds. Different variety seed that is available is often stockpiled in farmer unions and cooperatives, and ineffective distribution mechanisms hinder the reach of existing seeds [10].

Moreover, the inability of companies to market seeds outside of government channels is a major stumbling block to the development of the formal seed sector in Ethiopia. For example, the majority of Pioneer's production is marketed through ESE and/or BoARD channels, although it also has a small network of seed dealers that sell Pioneer seed independently. As long as private producers do not have the opportunity to market their own products through dealers then the advantages from a competitive private sector will not be realized, since selling to a single customer (the government) does not allow for a dynamic private seed sector (ibid).

In countries like Ethiopia where the formal seed supply is inefficient, the informal system is extremely important for seed security of the nation. The majority of Ethiopian smallholder farmers are largely dependent on this system mainly through farm-saved seed exchange. The system is providing cheaper and readily available in the farmers village at the right time and right place. As a result, the majority of Ethiopian farmers show a tendency of depending on the informal system. The informal seed system is more reliable and sustainable, and thus need to be strengthened with special emphasis of formalizing the system through integration with the law-regulated formal system [11].

The overall annual average seed requirement for cereals, pulses and oil crops is estimated to be over 400,000 tons [12]. However; the average yearly supply of improved seed doesn't exceed 20,000 tons since the establishment of ESE. One of the reasons for the mismatch is that there is limited capacity to supply as much source seed as demanded and multiplication of initial seed, which subsequently delivered to mass producers, is not supported by irrigation and almost totally depend on main season rainfall. Moreover, seed production supply system in the country has focused only on hybrid maize and wheat varieties that limited farmers option to other beneficial crops (ibid).

In west Gondar zone Sesame and Sorghum are the major crops that widely used for consumption and marketing purposes. Hence, the utilization of improved inputs is critical to improve the production and productivity of Sesame and Sorghum crops. Despite this fact, the attention given for seed production and supply is very low and it does not meet the growing demands of the farmers in the study area. This indicates that there are different factors directly or indirectly influencing the input supply system that believed to boost up production and productivity of the smallholder farmers. But the reasons why input-supplying system failed to satisfy the needs of the farmers is not analyzed so far in the study area.

Therefore, this study focuses on the identification of influential factors contributing for the inefficient seed supply and distribution system by giving special emphasis on sorghum and sesame crops. Moreover, the critical analysis of seed supply actors, their linkage in the seed supply system and mapping the Sesame and sorghum seed supply chain could be imminent to balance the growing demands of improved seeds in West Gondar zone. 


\subsection{Objectives of the Study}

\subsubsection{General Objective}

The general objectives of the study is to analyse Determinants of the adoption of improved Sorghum and Sesame seeds in West Gondar Zone

\subsubsection{Specific Objective}

i. To assess the extent of the adoption of improved Sorghum and Sesame Seeds

ii. Identify the factors affecting the adoption of improved Sorghum and Sesame Seeds

\section{Research Methodology}

\subsection{Description of the Study Area}

West Gondar zone has four districts and three city administrations. It is located in the North-western part of the country capital city Addis Ababa about $800 \mathrm{~km}$. The boundaries of the West Gondar Zone adjoin North gondar and Tigray region to the North, Ageawe zone and West Gojam zone to the South, Central Gondar zone to the East and Sudan to the West. This study was conducted by taking two purposively selected samples districts from West Gondar Zone.

\subsection{Sampling Techniques and Procedures}

To conduct this study a multi stage purposive and simple random sampling technique were applied. In the first stage Metema and Quara woredas were selected purposively from west Gondar zone, due to their potential for sorghum and sesame production. At the second stage, two kebeles were selected from each district purposively, depending on their potential to sorghum and sesame production and homogeneity to the other kebeles. At the last stage, a total of 150 sample household heads was selected from sample kebeles proportionally to target population size by using systematic random sampling technique.

\subsection{Data Types, Sources and Methods of Data Collection}

Both quantitative and qualitative methods of data were collected from primary and secondary sources in connection with all the information needed to answer the research questions. A structured household head interview was conducted using a structured questionnaire with closed ended questions. Before the formal survey pilot test was undertaken with 15 non sampled respondents from other kebeles with similar socio economic and agro ecological contexts to the sample kebeles and necessary modification was done accordingly.

Household head interviews were used to collect quantitative data pertaining to household socio economic characteristics, identification of factors affecting the adoption of improves sesame and sorghum variety. A total of $15 \mathrm{Key}$ informants' interviews were conducted using an interview checklist guide of items for discussion with District
Agricultural Officers, unions, and primary cooperatives in the target areas to solicit information on access to and adoption of improved seeds. Also, four focus group discussions was conducted with 10 participants in selected districts for indepth understanding on the factors affecting adoption.

Secondary data was collected from governmental and nongovernmental organizations both at zonal and district level. The secondary data was obtained from government annual reports, zonal and district agricultural office reports, and research results undertaken in the area. The secondary data was used to crosscheck and supplement primary data.

\subsection{Methods of Data Analysis}

Once the data are collected, coded and edited, the analysis was done with the support of SPSS software version 20 and stata 16 softeware. Descriptive statistics like frequency, mean, and standard deviation was used to analyze quantitative personal and socio- economic characteristics of the respondents. Furthermore, inferential statistics like Chisquare and T-test was used to evaluate whether there are significant relationships between different dummy/categorical and continuous variables respectively. On the other hand, the qualitative data was analyzed through narrations and descriptions.

Adoption index was used to analyze the extent of adoption of Sesame and Sorghum verities. To analyze the determinants of the adoption of improved Sesame and Sorghum verities the Binary Logit Model was adopted since the dependent variable is dichotomous while the independent variables are the combination of both dichotomous and continuous variables. Thus, The Logit Model helps the prediction of probability that a farmer does adopt or not adopt a technology based on given variables.

Specification of the Logit Model

According to Menard [13], Logit Model for the log odds of improved variety adoption of improved crop varieties can be specified as:

$$
\operatorname{Logit}(\mathrm{Y})=\beta \mathrm{o}+\beta 1 \mathrm{X} 1+\beta 1 \mathrm{X} 2+\ldots+\beta \mathrm{kXk}
$$

We can convert logit $(\mathrm{Y})$ back to the odds ratio by exponentiation [odds the $\mathrm{Y}=1$ ] $\mathrm{e}^{\text {logit }(\mathrm{Y})}$. Odds $(\mathrm{Y}=1) \mathrm{e}^{\ln [\operatorname{lodds}(\mathrm{Y}=1)}$. Again, we can convert the odds back to the probability that $(\mathrm{Y}=1)$ by the formula $\mathrm{P}(\mathrm{Y}=1)=[$ odds that $\mathrm{Y}=1] /[1$ +odds that $Y=1]$, where $P$ the conditional probability that a farmer adopted an improved variety. The conditional probability that a farmer does not adopt an improved variety is given by (1$\mathrm{Pi})=\operatorname{Prob}(\mathrm{y}=0) . \operatorname{Bsi}=\operatorname{prob}(\mathrm{Y}=1)$ is the conditional probability that a farmer adopted an improved variety. The conditional probability that a farmer does not adopt an improved variety is given by $(1-\mathrm{Pi})=\operatorname{Prob}(\mathrm{y}=0)$. Bs are parameters to be estimated and Xs are the set of independent variables. Some researchers name Logit with categorical independent variables Logit Models and with the one with mixed categorical and continuous independent variables Logistic Regression Models. Other researchers do not make distinctions between the two. In this study, the term Logit 
Model is used regardless of the type of explanatory variables included following that of [14].

\subsection{Hypothesis and Definition of the Explanatory Variables}

Sex of the household heads: Sex is a dummy variable that represents being maleness or femaleness. It takes the value 1 if the household head is male and 0 otherwise. Male household heads are expected to be better adopter than female household heads. Thus, positive relationship is expected.

Age of the household heads: It is a continuous variable that can be measured in the number of years. As the age of the household head increases the probability to adopt an improved variety decreases. On the other hand, when household is getting older he/she could have experiences and assets to utilize improved varieties. Hence, Age of the household head is either positively or negatively influence improved variety adoption.

Household size: it is a continuous variable that represents the total number of household members in adult equivalent. A larger household provide more labor thus expected to positively influence adoption of improved varieties of maize.

Education level of the household size: it is a dummy variable that takes the value of 1 if the household head is literate and 0 otherwise. It is clear that as the level of education increases the households exposure to new ideas and information increased and hence, enables the household head to adopt improved varieties. Education is expected to influence improved variety adoption positively.

Farm size in ha: It represents the total farm land size in ha. Farmland size was shown to positively influence the adoption decision of improved seeds in the drought-prone area of Ethiopia [15]. This is because households with large land are risk takers and have potential to buy improved seeds. Thus, in this study Farm size is expected to have positive influence on the adoption of improved varieties.

Livestock size: It is a continuous variable measured in TLU. Large livestock size creates good capital for the household that further enables them to purchase improved varieties. Thus, it is expected to influence improved variety adoption.

Extension contact: it is a continuous variable that represents the number of times a household head contact with development agents within a year. The frequency of extension workers' visits is expected to positively influence farmers' adoption decision.

Market distance: it is the distance between household home and the nearest local market and measured in $\mathrm{km}$. [16] noted the negative and significant association of market distance with the adoption of improved maize. This indicates that a farmer living at a distance from market centres is less likely to adopt improved maize varieties than those who are located closer. Thus, it is expected that the closer the local market is the higher the probability of improved variety adoption.

Road distance: it represents the distance between household heads home and the nearest road in $\mathrm{km}$. It is expected that the closer the nearer the road is the higher the probability of improved variety adoption.

Total household crop income: it represents the total crop production income in one production year measured in birr. It is expected that better total household crop income increases the probability of adopting improved Sesame and Sorghum varieties.

\section{Result and Discussion}

The rural household's adoption of improved sesame and sorghum seed technologies were influenced by demographic, socio-economic, institutional and psychological factors. Adoption of these technologies by farm households to the context of this study was therefore, measured in terms of technology users and non-users. The results of the study indicated that for both the technologies 83 (36.4\%) of the sampled farm households were found to be adopters, whereas the remaining $145(63.6 \%)$ were non-adopters (table 1$)$.

Table 1. Category of adoption on improved sesame and sorghum seed variety.

\begin{tabular}{llll}
\hline \multirow{2}{*}{ S. N. } & \multirow{2}{*}{ Technology type } & Adoption category & \\
\cline { 3 - 4 } & & Adopter Frequency (\%) & Non-adopter Frequency (\%) \\
\hline 1 & Imp. sesame seed variety & $83(36.4)$ & $145(63.6)$ \\
2 & Imp. sesame seed variety & $83(36.4)$ & $147(63.6)$ \\
\hline
\end{tabular}

Source: survey result (2018).

Numbers in parentheses indicate percentages.

\subsection{Descriptive Statistics of Selected Variables}

In order to have a clear picture of the quantitative demographic, socio-economic, institutional and communication variables which differentiate between improved sesame and sorghum seed adopters from the non- adopters t-test and chi-square test was applied. Four continuous and two discrete variables for each of the improved seed varieties were found significant with $1 \%, 5 \%$ and $10 \%$ probability level.

Table 2. Mean differences of continuous variables for adopters and non-adopters of improved sesame variety.

\begin{tabular}{|c|c|c|c|c|c|}
\hline \multirow{2}{*}{ S. No } & \multirow{2}{*}{ Variable } & \multirow{2}{*}{$\begin{array}{l}\text { Adopter }(\mathrm{N}=83) \\
\text { Mean }\end{array}$} & \multirow{2}{*}{$\begin{array}{l}\text { Non-adopter }(\mathrm{N}=145) \\
\text { Mean }\end{array}$} & \multirow{2}{*}{ T-value } & \multirow{2}{*}{ Sig. level } \\
\hline & & & & & \\
\hline 1 & AGE & $45.42(9.48)$ & $44.02(10.92)$ & 0.967 & 0.329 \\
\hline 2 & FMSIZE & $5.55(2.06)$ & $5.68(2.04)$ & -0.447 & 0.335 \\
\hline 3 & LANDSIZE & $7.03(3.43)$ & $6.11(5.11)$ & $1.467 * * *$ & 0.005 \\
\hline
\end{tabular}




\begin{tabular}{|c|c|c|c|c|c|}
\hline \multirow{2}{*}{ S. No } & \multirow{2}{*}{ Variable } & \multirow{2}{*}{$\begin{array}{l}\text { Adopter }(\mathrm{N}=83) \\
\text { Mean }\end{array}$} & \multirow{2}{*}{$\begin{array}{l}\text { Non-adopter }(\mathrm{N}=145) \\
\text { Mean }\end{array}$} & \multirow{2}{*}{ T-value } & \multirow{2}{*}{ Sig. level } \\
\hline & & & & & \\
\hline 4 & LSTOCKHO in TLU & $10.06(6.87)$ & $7.90(7.5)$ & 2.158 & 0.692 \\
\hline 5 & TOTALINCOME & $4.13(30729 . .02)$ & $5.00(34921.85)$ & $-1.889 * *$ & 0.021 \\
\hline 6 & FRETRAIN & $4.38(11.37)$ & $1.54(2.99)$ & $2.800 * * *$ & 0.000 \\
\hline 7 & FREDAVISIT & $1.56(3.24)$ & $0.60(1.61)$ & $2.987 * * *$ & 0.000 \\
\hline 8 & FARMEXP & $18.33(9.72)$ & $19.04(10.40)$ & -.517 & 0.638 \\
\hline 8 & DISMARKET & $3.36(4.52)$ & $3.45(4.11)$ & -0.154 & 0.182 \\
\hline 9 & DISMROAD & $2.81(4.49)$ & $2.37(2.89)$ & 0.762 & 0.173 \\
\hline
\end{tabular}

Source: survey result (2018).

*** and $* *$ represent level of significant at $1 \%$ and $5 \%$ respectively.

Numbers in parentheses indicate standard deviations.

Table 3. Percentage difference of discrete variables on adoption of improved sesame seed variety.

\begin{tabular}{|c|c|c|c|c|c|}
\hline \multirow{2}{*}{ Variables } & \multirow{2}{*}{ Value } & \multicolumn{2}{|c|}{ Improved sesame seed } & \multirow{2}{*}{ Chi-square value } & \multirow{2}{*}{ P-value } \\
\hline & & Adopter frequency & Non-adopter frequency & & \\
\hline \multirow[t]{2}{*}{ SEX } & 0 & $76(91.57)$ & $129(89)$ & 0.394 & 0.530 \\
\hline & 1 & $7(8.43)$ & $16(11)$ & & \\
\hline \multirow[t]{2}{*}{ EDLVL } & 0 & $21(25.3)$ & $45(31)$ & 1.480 & 0.477 \\
\hline & 1 & $62(74.7)$ & $100(69)$ & & \\
\hline \multirow[t]{2}{*}{ EXCONTACT } & 0 & $76(93.8)$ & $105(75)$ & $12.270 * * *$ & 0.000 \\
\hline & 1 & $5(6.2)$ & $35(25)$ & & \\
\hline \multirow[t]{2}{*}{ FERUSE } & 0 & $32(39.5)$ & $4(3.28)$ & $43.792 * * *$ & 0.000 \\
\hline & 1 & $49(60.5)$ & $118(96.72)$ & & \\
\hline \multirow[t]{2}{*}{ CREDITUSE } & 0 & $46(57.5)$ & $85(59.44)$ & 0.080 & 0.778 \\
\hline & 1 & $34(42.5)$ & $58(40.56)$ & & \\
\hline
\end{tabular}

Source: survey result (2018).

*** represent level of significant at $1 \%$ level respectively.

Numbers in parentheses indicate percentages.

Table 4. Mean differences of continuous variables for adopters and non-adopters of improved Sorghum variety

\begin{tabular}{|c|c|c|c|c|c|}
\hline \multirow{2}{*}{ S. No } & \multirow{2}{*}{ Variable } & \multirow{2}{*}{$\begin{array}{l}\text { Adopter }(\mathbf{N}=\mathbf{8 3}) \\
\text { Mean }\end{array}$} & \multirow{2}{*}{$\begin{array}{l}\text { Non-adopter }(\mathrm{N}=145) \\
\text { Mean }\end{array}$} & \multirow{2}{*}{ T-value } & \multirow{2}{*}{ Sig. level } \\
\hline & & & & & \\
\hline 1 & AGE & $45.19(9.88)$ & $44.16(10.73)$ & 0.706 & 0.688 \\
\hline 2 & FMSIZE & $5.56(2.14)$ & $5.68(2.0)$ & -0.431 & 0.135 \\
\hline 3 & LANDSIZE & $6.87(3.84)$ & $6.21(4.93)$ & 1.038 & 0.169 \\
\hline 4 & LSTOCKHO in TLU & $9.81(8.17)$ & $8.07(6.78)$ & $1.721 *$ & 0.053 \\
\hline 5 & TOTALINCOME & $4.49(32087.27)$ & $4.78(34542.54)$ & -0.622 & 0.232 \\
\hline 6 & FRETRAIN & $2.81(7.36)$ & $2.46(7.44)$ & .339 & 0.727 \\
\hline 7 & FREDAVISIT & $3.2(1.30)$ & $2.53(1.10)$ & $3.887 * *$ & 0.040 \\
\hline 8 & FARMEXP & $19.09(10.57)$ & $18.62(9.93)$ & .332 & 0.250 \\
\hline 9 & DISMARKET & $3.45(4.80)$ & $3.40(3.94)$ & $.082 * *$ & 0.013 \\
\hline 10 & DISMROAD & $2.25(5.20)$ & $2.13(3.30)$ & $1.961 * * *$ & 0.000 \\
\hline
\end{tabular}

Source: survey result (2018).

$* * *, * *$ and * represent level of significant at $1 \%, 5 \%$ and $10 \%$ level respectively.

Numbers in parentheses indicate standard deviations.

Table 5. Percentage difference of discrete variables on adoption of improved sorghum seed variety.

\begin{tabular}{|c|c|c|c|c|c|}
\hline \multirow{2}{*}{ Variables } & \multirow{2}{*}{ Value } & \multicolumn{2}{|c|}{ Improved sesame seed } & \multirow{2}{*}{ Chi-square value } & \multirow{2}{*}{ P-value } \\
\hline & & Adopter frequency & Non-adopter frequency & & \\
\hline \multirow[t]{2}{*}{ SEX } & 0 & $73(90.1)$ & $130(89.7)$ & 0.006 & 0.937 \\
\hline & 1 & $8(9.9)$ & $15(10.3)$ & & \\
\hline \multirow[t]{2}{*}{ EDLVL } & 0 & $20(24.1)$ & $45(31)$ & 1.729 & 0.421 \\
\hline & 1 & $63(75.9)$ & $100(69)$ & & \\
\hline \multirow[t]{2}{*}{ EXCONTACT } & 0 & $69(89.6)$ & $112(77.8)$ & $4.739 * *$ & 0.029 \\
\hline & 1 & $8(10.47)$ & $32(22.2)$ & & \\
\hline \multirow[t]{2}{*}{ FERUSE } & 0 & $25(33.3)$ & $1(0.8)$ & $44.279 * * *$ & 0.000 \\
\hline & 1 & $50(66.7)$ & $125(99.2)$ & & \\
\hline CREDITUSE & 0 & $49(62.0)$ & $82(56.9)$ & 0.543 & 0.461 \\
\hline
\end{tabular}




\begin{tabular}{lllll}
\hline \multirow{2}{*}{ Variables } & \multirow{2}{*}{ Value } & \multicolumn{2}{l}{ Improved sesame seed } & \multirow{2}{*}{ Chi-square value } \\
\cline { 2 - 3 } & & Adopter frequency & Non-adopter frequency & \\
\hline & 1 & $30(38.0)$ & $62(43.1)$ \\
\hline
\end{tabular}

Source: survey result (2018).

$* * *, * *$ represent level of significant at $1 \%$ and $5 \%$ level respectively.

Numbers in parentheses indicate percentages.

\subsection{Model Output}

In the preceding section, variables characterizing the farm households and their differences among the adopter and nonadopter of improved sesame and sorghum varieties groups were identified. However, in the logit model analysis, we emphasize on considering the combined effect of variables between adopter and non-adopter of the two varieties farm households in the study area. Therefore, the emphasis is on analyzing the variables together, not one at a time. By considering the variables simultaneously, we are able to incorporate important information about their relationship.

Fifteen variables were hypothesized to explain factors affecting smallholder farmer's adoption of improved sesame and sorghum seed varieties. Out of these four of the variables for each of the improved varieties were found to be significant, while the remaining eleven were less significant in explaining the variations in the dependent variable.

The maximum likelihood estimates of the logistic regression model show that livestock holding in TLU (LSTOCKHO), farming experience (FARMEXP), fertilizer use (FERUSE) and total income (TOTALINCOME) were important and significant factors influencing smallholder farmers adoption improved sesame seed variety in the study area (Table 6).

From the variables hypothesized affecting adoption of improved sorghum seed variety livestock holding in TLU (LSTOCKHO), fertilizer use (FERUSE), distance from market (DISMARKET) and distance from the main road (DISMROAD) were powerful in explaining smallholder farmers' adoption of improved sorghum seed variety.

Table 6. Maximum likelihood estimates of logit model and the effects of explanatory variables on the probability of adoption of improved sesame seed variety.

\begin{tabular}{|c|c|c|c|c|}
\hline Explanatory Variables & Estimated coefficient & Odds ratio & Wald statistics & Significance level \\
\hline Constant & -6.212 & .002 & 7.323 & .007 \\
\hline AGE & -.038 & .963 & 2.228 & .135 \\
\hline SEX & -.779 & .459 & 1.532 & .216 \\
\hline EDLVL & -.455 & .635 & 1.011 & .335 \\
\hline FMSIZE & .082 & 1.085 & .588 & .443 \\
\hline LANDSIZE & -.033 & .967 & .314 & .575 \\
\hline FARMEXP & .073 & 1.076 & $6.763 * * *$ & .009 \\
\hline FERUSE & 4.295 & 73.350 & $29.092 * * *$ & .000 \\
\hline EXCONTACT & .881 & 2.414 & 1.824 & .177 \\
\hline FRETRAIN & -.001 & .999 & 0.001 & .982 \\
\hline FREDAVISIT & .014 & 1.014 & .010 & .920 \\
\hline TOTALINCOME & .000 & 1.000 & $11.897 * * *$ & .001 \\
\hline DISMARKET & -.012 & .988 & .029 & .865 \\
\hline CREDITUSE & -.455 & 0.635 & 1.011 & 0.315 \\
\hline
\end{tabular}

Source: own survey result (2018).

*** represent level of significant at $1 \%$.

Table 7. Maximum likelihood estimates of logit model and the effects of explanatory variables on the probability of adoption of improved sorghum seed variety.

\begin{tabular}{lllll}
\hline Explanatory Variables & Estimated coefficient & Odds ratio & Wald statistics \\
\hline Constant & -7.189 & .001 & 8.806 & Significance level \\
AGE & .001 & 1.001 & .002 & .003 \\
SEX & -.068 & .934 & .012 & .968 \\
EDLVL & -.172 & .842 & .176 & .863 \\
FMSIZE & .092 & 1.092 & .791 & .675 \\
LANDSIZE & -.045 & .956 & $.075 * * *$ & .353 \\
LSTOCKHO & -.085 & .919 & .769 & .004 \\
FARMEXP & .021 & 1.022 & .374 \\
FERUSE & 3.436 & 31.068 & $.037 *$ \\
EXCONTACT & .957 & 2.604 & .000 \\
FRETRAIN & -.043 & .958 & .883 \\
FREDAVISIT & .034 & 1.034 & .081 \\
\hline
\end{tabular}




\begin{tabular}{lllll}
\hline Explanatory Variables & Estimated coefficient & Odds ratio & Wald statistics & Significance level \\
\hline TOTALINCOME & .000 & 1.000 & 1.748 & 0.186 \\
DISMARKET & .153 & 1.166 & $2.982^{*}$ & .084 \\
DISMROAD & -.145 & .865 & $3.110^{*}$ &. .078 \\
CREDITUSE & .080 & 1.083 & .043 & .836 \\
\hline
\end{tabular}

Source: survey result (2018).

***and * represent level of significant at $1 \%$ and $10 \%$ respectively.

\subsubsection{Level of Adoption of the Technology}

Adopters experience of using improved sesame and sorghum seed varieties ranges from 1-18 years. Only limited number of farmers has long years of using these improved varieties. The under lined table indicates years of their experience. The minimum year of practicing both varieties is one year and the maximum year for sesame seed variety is 18 years and for sorghum 15 years. The average year of using improved sesame seed was 3.4 years and for sorghum variety 3.3 years. In general, the majority $(83.1 \%$ for sesame and $81.7 \%$ for sorghum) of the adopters in both varieties has started using the technology since the last five years.

Table 8. Years of experience of adopters in practicing the improved sesame and sorghum seed varieties

\begin{tabular}{|c|c|c|c|c|c|c|c|}
\hline \multirow{2}{*}{ S. $\mathbf{N}$} & \multirow{2}{*}{ Variety } & \multicolumn{6}{|c|}{ Adopters with the number of years practicing the variety } \\
\hline & & 1-5 years & 6-10 years & $>10$ years & Min. year & Max. year & Mean year \\
\hline 1 & Improved Sesame Seed & $69(83.1)$ & $10(12.1)$ & $4(4.8)$ & 1 & 18 & 3.4 \\
\hline 2 & Improved Sorghum Seed & $67(81.7)$ & $12(14.6)$ & $3(3.7)$ & 1 & 15 & 3.3 \\
\hline
\end{tabular}

Among the different packages expected from farmers to use or practice with the improved crop varieties is proper use of fertilizer. Adopter respondent farmers were asked whether they apply chemical fertilizer for improved sesame and sorghum seed variety. Among 83 improved sesame seed adopter farmers only $12 \%$ were applying fertilizer with improved sesame seed variety which is insignificant when tested by chi-square at 5\% significant level. In addition, farmers used compost or manure to fertilize their land when they have small plots of land. Considering these option farmers were also requested if they apply compost for improved sesame seed and the result of the study revealed that only 12 or $14.5 \%$ were applying manure for the crop in the study year. Therefore, the level adoption with regard to applying package components with the crop is very low.

However, the numbers of improved sorghum seed adopters are more as compared with improved seed adopters to apply chemical fertilizer and compost with the technology. 32.9\% and $25.6 \%$ of the respondents were applying chemical fertilizer and compost respectively with improved sorghum seed. The remaining or the majority of the adopters were growing improved sorghum seed without applying fertilizer.

In general, the level of adopting both technologies were very low considering the application of chemical fertilizer and manure from the recommended package.

\subsubsection{Non-adopters of Both Improved Seed Technologies}

The majority of the farmers did not adopt both sesame and sorghum seed variety until the study year. They were requested to rate the basic reasons that hindered them not to adopt the technologies by providing response categories as listed below in the table.

Among 145 non-adopter respondent farmers for improved sesame seed, from the given nine causes that may be a problem hindering them not to adopt the technology five were voted by the majority.

On the other hand, 147 non-adopter respondent farmers of improved Sorghum seed, from the given nine causes that may be a problem hindering them not to adopt the technology three were voted by the majority.

Table 9. Problems hindering farmers not to adopt both seed technologies.

\begin{tabular}{llllll}
\hline \multirow{2}{*}{ S. No } & \multirow{2}{*}{ variables } & \multicolumn{2}{c}{ Sesame seed non-adopters } & \multicolumn{2}{c}{ Sorghum seed non-adopters } \\
\cline { 3 - 6 } & & Yes (\%) & NO (\%) & Yes (\%) & NO (\%) \\
\hline 1 & Lack of interest on the variety & 18 & 127 & 16 & 131 \\
2 & Not available on time & 105 & 40 & 103 & 44 \\
3 & It is expensive to buy & 80 & 65 & 74 & 173 \\
4 & Low in quality & 18 & 126 & 13 & 1234 \\
5 & Poor supply of the improved sesame seed & 82 & 63 & 72 & 753 \\
6 & Lack of awareness & 81 & 64 & 74 & 734 \\
7 & Inability to use the technology & 70 & 75 & 64 & 835 \\
8 & Poor test of the variety for food & 6 & 139 & 6 & 1416 \\
9 & Lack of information & 24 & 121 & 23 & 1247 \\
\hline
\end{tabular}

Source: own survey result (2018). 


\section{Conclusion and Recommendation}

\subsection{Conclusion}

Seed is a key input for improving crop production and productivity. Increasing the quality of seeds can increase the yield potential of the crop by significant folds. The rural household's adoption of improved sesame and sorghum seed technologies were influenced by demographic, socioeconomic, institutional and psychological factors. Adoption of these technologies by farm households to the context of this study was therefore, measured in terms of technology users and non-users. The results of the study indicated that for both the technologies $83(36.4 \%)$ of the sampled farm households were found to be adopters, whereas the remaining $145(63.6 \%)$ were non-adopters.

The maximum likelihood estimates of the logistic regression model show that livestock holding in TLU (LSTOCKHO), farming experience (FARMEXP), fertilizer use (FERUSE) and total income (TOTALINCOME) were important and significant factors influencing smallholder farmers adoption improved sesame seed variety in the study area.

\subsection{Recommendation}

Seed is a key input for improving crop production and productivity. Increasing the quality of seeds can increase the yield potential of the crop by significant folds and thus, is one of the most economical and efficient inputs to agricultural development. The utilization of improved inputs is critical to improve the production and productivity of Sesame and Sorghum crops. Hence, the concerned body has to give the attention to increase for seed production and supply and has to meet the growing demands of the farmers in the study area. The different factors directly or indirectly influencing the input supply system that believed to boost up production and productivity of the smallholder farmers has to be give a great emphasis.

\section{Conflict of Interest}

The authors declare that they have no conflict of interest.

\section{Data Availability}

All relevant data are within the paper and its supporting information files.

\section{Acknowledgements}

We are grateful to the diverse research teams from university of Gondar and the staff of the Agriculture and rural transformation college for guiding, managing, and assisting in data collection in our survey, and many development agents' assistants for their assistance with data collection.

Compliance with ethical standards.

\section{References}

[1] Agriculture in the developing world: connecting innovation in plant breeding research to downstream applications. PNAS102 (44): 15739-15746.

[2] Recent Development in Seed Systems of Ethiopia.

[3] A baseline survey on the Ethiopian seed sector. The African seed trade association. October, 2010. Addis Ababa, Ethiopia.

[4] Seeds of confusion: the impact of policies on seed systems. Dissertation. Wageningen: Wageningen University.

[5] Ethiopian Agricultural Sample Enumeration, 2001/2002 (1994 E. C.). Results at country level. Statistical report on farm management practices, livestock and farm implements. Part 2. Addis Ababa: Central Statistical Authority.

[6] The status of the Ethiopian seed industry and the role of the Ethiopian Seed Enterprise. In: Farmers' seeds and varieties: supporting informal seed supply in Ethiopia. 23-33. Wageningen: Wageningen International.

[7] Commercialization of Ethiopian agriculture: Extension service from input supplier to knowledge broker and facilitator. IPMS (Improving Productivity and Market Success) of Ethiopian farmers project working paper 1. ILRI (International Livestock Research Institute), Nairobi, Kenya. 36p.

[8] FAO/WFP Crop and Food supply assessment mission to Ethiopia, 24 February 2008.

[9] Central Statistical Authority of Ethiopia, 2005-2010. Annual Agricultural Sample Survey Report. Addis Ababa, Ethiopia.

[10] Seed system potential in Ethiopia: Constraints and opportunities for enhancing the seed sector. International Food Policy Research Institute.

[11] A baseline survey on the Ethiopian seed sector. The African seed trade association. October, 2011. Addis Ababa, Ethiopia.

[12] Marja HT, B Zewdie, B Abdurahman and S Walter (2008). Farmers, Seeds and Varieties. Wageningen International, the Netherlands.

[13] Menard, S (2002). Applied Logistic Regression Analyis Sage Publications, Inc.

[14] Liao, T. F (1994). Interpreting Probability Models Logit, Probit, and Other generalized Linear Models. Sage University paper Series on Qunatitative Applications in the social sciences. California: Sage. Thousand Oaks.

[15] Access to Seed and Variety Adoption of Farmers in Ethiopia: A Case of Open Pollinated Maize in Drought-Prone Central Rift Valley. Dissertation Submitted in Partial Fulfillment of the Requirements for Degree of Doctor of Philosophy in International Development Graduate School of International Development, Nagoya University.

[16] Feleke, S. and Zegeye, T (2005). Adoption of improved maize varieties in Southern Ethiopia. 